\title{
A giant myxoma originating from the aortic valve causing severe left ventricular tract obstruction: a case report and literature review
}

\author{
Edvin Prifti ${ }^{1}$, Fadil Ademaj ${ }^{2}$, Efrosina Kajo ${ }^{1}$ and Arben Baboci ${ }^{1}$
}

\begin{abstract}
Introduction: The left ventricular localization of a myxoma is very rare, usually arising from the interventricular septum close to the left ventricular outflow tract, the mitral valve, the ventricular wall and extremely rarely the aortic valve.
\end{abstract}

Case presentation: A 13-year-old male was admitted due to dyspnea and angina. Transesophageal echocardiography revealed left ventricular outflow tract obstruction with a mean gradient of $58 \mathrm{mmHg}$, and a mobile mass measuring $65 \times 25 \mathrm{~mm}$ originating from the ventricular surface of the aortic valve was identified. The patient underwent urgent surgical excision and aortic valve replacement. Histopathological examination of the mass confirmed the diagnosis of a myxoma.

Conclusion: In conclusion, a myxoma originating from the aortic valve remains a very rare localization. Total resection associated with aortic valve replacement seems to offer an excellent outcome.

Keywords: Aortic valve, Myxoma, Left ventricular tract obstruction

\section{Background}

Most cardiac myxomas are located in the left atrium, attached to the interatrial septum. The left ventricular localization of a myxoma is very rare, usually arising from the interventricular septum close to the left ventricular outflow tract [1-3], the mitral valve [4,5], the left ventricular wall [6] and extremely rarely the aortic valve [7]. Here we report a case of an aortic valve myxoma undergoing successful resection.

\section{Case presentation}

A 13-year-old male patient was admitted due to dyspnea and angina. On physical examination, peripheral pulses were present and normal. An early diastolic murmur could be heard in the aortic valve area. The ECG showed a normal sinus rhythm with signs of mild left ventricular hypertrophy. Transesophageal echocardiography revealed a grade II/IV aortic incompetence and left ventricular outflow tract obstruction with a peak gradient of

\footnotetext{
* Correspondence: fadilademaj-kosove@hotmail.com

${ }^{2}$ Division of Cardiology, Regional Hospital of Gjakova, Rr. Prizren, Gjakova, Kosovo

Full list of author information is available at the end of the article
}

$110 \mathrm{mmHg}$ and a mean gradient of $58 \mathrm{mmHg}$, and a giant mobile mass originating from the ventricular surface of the aortic valve was identified (Figure 1A). LV function was normal. The other cardiac valves and cavities were free of lesions. The patient underwent urgent surgical excision through a median sternotomy under normothermic cardiopulmonary bypass. The aorta was clamped and an anterior cardioplegic solution was administered. An anterior oblique aortotomy was performed. The inspection of the aortic valve revealed a $65 \times 25 \mathrm{~mm}$ mass, attached to the ventricular surface of the right and left coronary leaflets (Figure 1B). The mass was gelatinous soft (Figure 1C) with multiple haemorrhagic areas and was totally excised (Figure 1D). The patient underwent standard aortic valve replacement with mechanical prosthesis. Histopathological examination demonstrated a sparse population of round and stellate cells mostly concentrating beneath the surface, with some cells forming solid cords and vascular channels (Figure 2A), surrounded by abundant myxoid stroma (Figure 2B) confirming the diagnosis of a myxoma. Mitosis, pleomorphism and necrosis were all absent. The postoperative course was uneventful. The patient was 


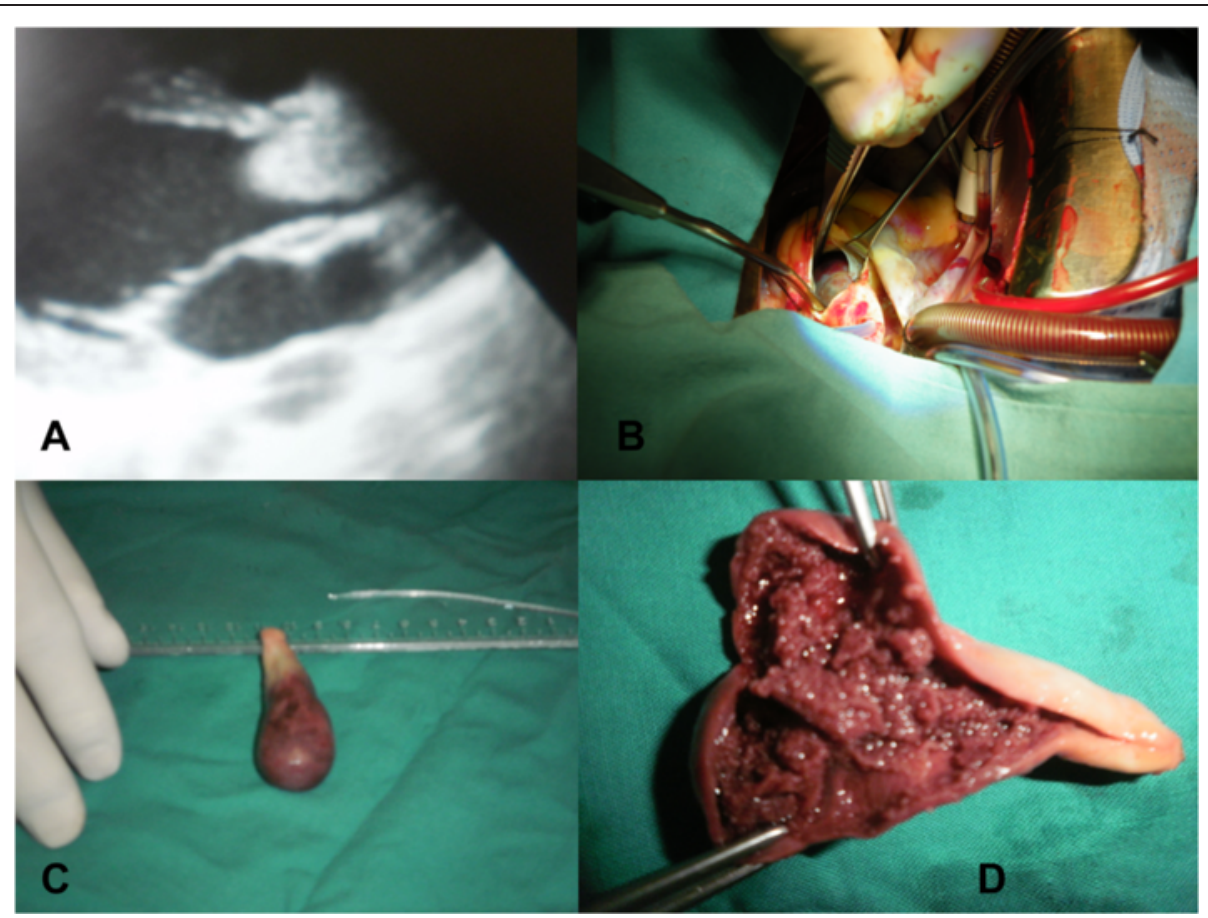

Figure 1 Transthoracic echocardiography, aortotomy, and excision and division of the mass. (A) Transthoracic echocardiography revealing a mass at the left ventricular outflow tract. (B) Aortotomy was performed and the mass visualized underneath the aortic valve. (C) The total excised mass. (D) The mass was divided and multiple haemorrhagic areas discovered.

followed up for 3 years postoperatively with a series of echocardiography control. Non-tumour recurrence was diagnosed.

\section{Discussion}

Myxomas of the left ventricle are very rare. Recently, a thorough literature review demonstrated only 71 cases with a reported left ventricular myxoma usually originating from the interventricular septum [6]. Myxomas of the cardiac valves are very unusual, especially those of the aortic valve. To our knowledge, this is the tenth reported case of an aortic valve myxoma. The first was described as a post-mortem finding [8]. However, the patient in the present case is the youngest amongst them.

The shape, the extension, the site of attachment, the involvement of valve leaflets and the functional obstruction of the LV outflow tract could promptly and easily be assessed by echocardiography. Transesophageal echocardiography enables the detection of an aortic valve myxoma; however, histopathology remains the gold standard method of diagnosis. Most of the tumours were larger than $1 \mathrm{~cm}$; however, the present case had the greatest mass dimensions amongst the reported cases with an aortic valve myxoma.
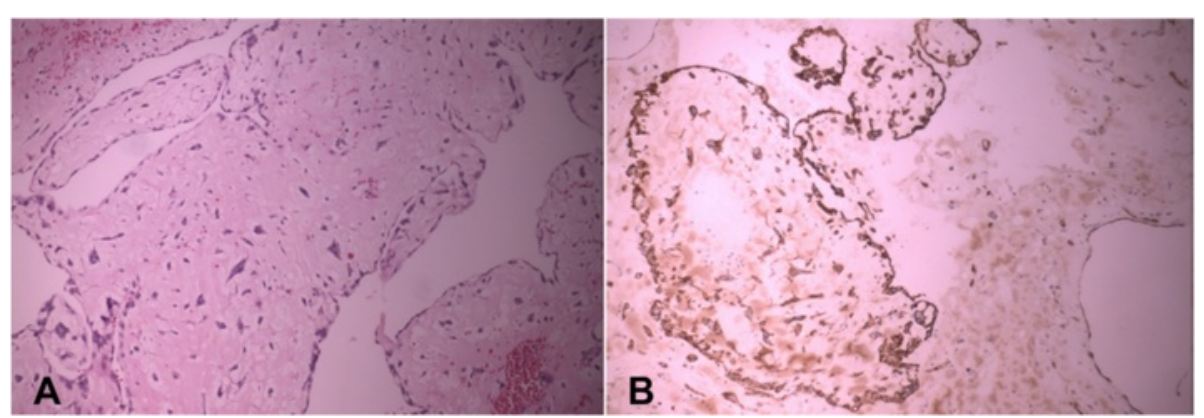

Figure 2 Histopathological examination. (A) The myxoma cells with a stellate appearance proliferate in a myxoid background in nests and linear syncytia, which often appear to emanate from vascular structures (H-E, 10X). (B) The myxoma cells variably express endothelial cell markers $(C D$ 34, 20x). 
Table 1 Clinical presentations of the reported cases and the present case

\begin{tabular}{|c|c|c|c|c|c|c|c|}
\hline Reference & Age & Clinical finding & Size & Complication & Associated procedure & Location & Comorbidity \\
\hline Kennedy et al. [13] & 23 & Leg pain & $1.5 \mathrm{~cm}$ & PVD & AVR & RCC and LCC & None \\
\hline Watarida et al. [9] & 58 & Heart murmur & $1.1 \times 1 \mathrm{~cm}$ & None & AVR & $\mathrm{RCC}$ & HTN \\
\hline Ramsheyi et al. [10] & 32 & Facial hemiparesis & $1 \mathrm{~cm}$ & Stroke & AVR & $\mathrm{RCC}$ & None \\
\hline Okamoto et al. [11] & 61 & Endocarditis & $1 \times 1 \mathrm{~cm}$ & None & None & LCC & HTN, DM \\
\hline Dyk et al. [12] & 15 & Chest pain & $4 \times 1 \mathrm{~cm}$ & STEMI & None & NCC & None \\
\hline Koyalakonda et al. [15] & 60 & Paroxysmal A-fib & $1 \times 1 \mathrm{~cm}$ & Stroke & None & $\mathrm{RCC}$ & A-fib, HTN \\
\hline Kim et al. [16] & 72 & Shortness of breath & $1.5 \times 0.8 \mathrm{~cm}$ & None & AVR & NCC & HTN, A-fib \\
\hline Fernandez et al. [14] & 28 & Hemiparesis & $1.5 \times 0.7 \mathrm{~cm}$ & Stroke & AVR & RCC and LCC & Epilepsy \\
\hline Javed et al. [7] & 81 & Leg pain & $1.8 \times 1.2 \mathrm{~cm}$ & $\mathrm{AMI}$ & CABG & LCC & HTN, AA \\
\hline This study & 13 & Dyspnea and angina & $60 \times 22 \mathrm{~mm}$ & None & AVR & RCC and LCC & None \\
\hline
\end{tabular}

AVR, aortic valve replacement; CABG, coronary artery bypass grafting; DM, diabetes mellitus; HTN, hypertension; LCC, left coronary cusp; NCC, non-coronary cusp; RCC, right coronary cusp; PVD, peripheral vascular disease; AMI, acute myocardial infarction; STEMI, ST segment elevation myocardial infarction.

Our patient referred dyspnea and angina. The clinical presentations of the other seven reported cases included acute embolic stroke, acute embolic myocardial infarction, acute embolic lower limb ischaemia and aortic stenosis (Table 1). An aortic valve myxoma has been described as arising from both the ventricular aspect [9-11] and the margin of the valve cusps [12]. The right, left and non-coronary leaflets may be affected either together or individually (Table 1). In the other two reported cases $[13,14]$, the right and left cusps were simultaneously affected as in our patient.

Differential diagnosis of an aortic valve myxoma includes vegetations, papillary fibroelastoma and Lambl's excrescences. Microscopic and immunohistochemical characteristics allow the distinction between these entities. As we have observed, aortic valve myxomas are a potential source of emboli; therefore, surgical removal should be indicated as soon as the diagnosis is confirmed. Surgical excision should include not only the tumour but also the implantation site to minimize the risk of local recurrence. Tumour resection with conservation of the native valve should be intended, but sometimes due to a big tumour size and/or structural valve degeneration, replacement of the aortic valve may become necessary as in our case. These patients should be followed carefully due to a high probability of distal tumour growth at the site of previous embolization as well as local recurrence of the tumour.

\section{Conclusions}

In conclusion, a myxoma originating from the aortic valve remains a very rare left ventricular localization of such a tumour. Total resection associated with aortic valve replacement seems to offer an excellent outcome.

\section{Consent}

Written informed consent was obtained from the patient's legal guardian(s) for publication of this case report and any accompanying images. A copy of the written consent is available for review by the Editor-in-Chief of this journal.

\section{Competing interests}

The authors declare that they have no competing interests.

\section{Authors' contributions}

$E P$ and $A B$ performed the surgery. FA and EK performed the diagnosis and the manuscript writing including the literature review. All authors read and approved the final manuscript.

\section{Author details}

'Division of Cardiac Surgery, University Hospital Center of Tirana, Tirana, Albania. 'Division of Cardiology, Regional Hospital of Gjakova, Rr. Prizren, Gjakova, Kosovo.

Received: 15 November 2014 Accepted: 6 April 2015

Published online: 16 April 2015

\section{References}

1. Natale E, Minardi G, Casali G, Pulignano G, Musumeci F. Left ventricular myxoma originating from the interventricular septum and obstructing the left ventricular outflow tract. Eur J Echocardiogr. 2008;9(1):84-5.

2. Rao RV, Walsh S, Chan V, Stadnick E, Sohmer B, Veinot JP, et al. Unusual cause of an ejection murmur: myxoma in the left ventricular outflow tract. Can J Cardiol. 2013;29(12):1742.e13-5.

3. Kumar P, Garg A. Left ventricular myxoma in a child: a case report. Eur J Echocardiogr. 2011;12(3):E23.

4. Keeling IM, Oberwalder P, Schuchlenz H, Anelli-Monti M, Rigler B. Left ventricular outflow tract obstruction due to valve myxoma. Ann Thorac Surg. 2000;69:1590-1.

5. Choi BW, Ryu SJ, Chang BC, Choe KO. Myxoma attached to both atrial and ventricular sides of the mitral valve: report of a case and review of 31 cases of mitral myxoma. Int J Cardiovasc Imaging. 2001;17:411-6.

6. Abad C, Novoa J, Delgado A, Alonso A. Myxoma of the left ventricle. Tex Heart Inst J. 2014;41(4):395-400.

7. Javed A, Zalawadiya S, Kovach J, Afonso L. Aortic valve myxoma at the extreme age: a review of literature. BMJ Case Rep. 2014;18:2014.

8. Wold LE, Lie JT. Cardiac myxomas: a clinico-pathologic profile. Am J Pathol. 1980;101:219-33.

9. Watarida S, Katsuyama K, Yasuda R, Magara T, Onoe M, Nojima T, et al. Myxoma of the aortic valve. Ann Thorac Surg. 1997;63:234-6. 
10. Ramsheyi A, Deleuze P, D'Attelis N, Bical O, Lefort JF. Aortic valve myxoma. J Card Surg. 1998;13:491-3.

11. Okamoto T, Doi H, Kazui T, Suzuki M, Koshima R, Yamashita T, et al. Aortic valve myxoma mimicking vegetation: report of a case. Surg Today. 2006;36:927-9.

12. Dyk W, Konka M. Images in cardiothoracic surgery: unusual complication of aortic valve grape-like myxoma. Ann Thorac Surg. 2009;88:1022.

13. Kennedy P, Parry AJ, Parums D, Pillai R. Myxoma of the aortic valve. Ann Thorac Surg. 1995;59:1221-3.

14. Fernandez AL, Vega M, El-Diasty MM, Suárez JM. Myxoma of the aortic valve. Interact Cardiovasc Thorac Surg. 2012;15:560-2.

15. Koyalakonda SP, Mediratta NK, Ball J, Royle M. A rare case of aortic valve myxoma: an unusual cause of embolic stroke. Cardiology. 2011;118:101-3.

16. Kim HY, Kwon SU, Jang WI, Kim HS, Kim JS, Lee HS, et al. A rare case of aortic valve myxoma: easy to confuse with papillary fibroelastoma. Korean Circ J. 2012;42:281-3.

\section{Submit your next manuscript to BioMed Central and take full advantage of:}

- Convenient online submission

- Thorough peer review

- No space constraints or color figure charges

- Immediate publication on acceptance

- Inclusion in PubMed, CAS, Scopus and Google Scholar

- Research which is freely available for redistribution 